\title{
A PENOLOGIA dO ESTATUTO DE ROMA E A CONSTITUIÇÃo
}

\author{
Felipe Machado Caldeira ${ }^{1}$
}

\begin{abstract}
RESUMO
O estudo apresenta uma proposta de leitura das disposições sobre a teoria da pena do Estatuto de Roma a partir da matriz constitucional penal prevista na Constituição da República Federativa do Brasil de 1988. Para tanto, inicia-se por uma abordagem histórica, filosófica e jurídica da afirmação do direito internacional e da sedimentação do constitucionalismo, com considerações sobre a teoria dos direitos fundamentais. Por fim, conclui-se pela conformidade ou desconformidade das disposições estatutárias em relação às normas constitucionais, com a sua conseqüente necessidade de conformação e harmonização, ou a sua invalidação.
\end{abstract}

Palavras-chave: Estatuto de Roma. Constituição. Pena. Harmonização.

\begin{abstract}
The study shows a proposition of reading of the norms about penalty theory of the Rome Statute from the penal constitutional matrix provided in the Brazilian Federal Republic Constitution of 1988. Therefore, starts from a historical, philosophical and juridic view of the affirmation of the internationl Law and sedimentation of the constitucionalism, with considerations about fundamental rights theory. Concludes for the conformity or desconformity of the statutory norms and their relationship with the constitution, with its consequent need of conformation and alignment, or its invalidation.
\end{abstract}

Key words: Rome Statute. Constitution. Penalty. Alignment.

\section{INTRODUÇÃO}

Durante a Idade Contemporânea, especialmente a partir do século $\mathrm{XX}$, o desenvolvimento do Direito foi marcado, nos planos histórico, filosófico e jurídico, por dois grandes movimentos, um no plano internacional - a internacionalização do direito - e um no plano interno - a constitucionalização do direito.

No plano internacional, a afirmação do Direito Internacional, impulsionada pelos fenômenos da globalização econômica (cultural, social, jurídica, política etc.) e da integração regional, permitiu a superação de antiga controvérsia sobre a existência de um Direito Internacional; hodiernamente, esta existência é uma realidade incontestável - já se fala em um Direito Comunitário - e representa um novo horizonte de

\footnotetext{
${ }^{1}$ Mestre em Direito Penal pela UERJ, especialista em Direito Penal Econômico pelas Universidades de Coimbra (Portugal), Castilla-La Mancha (Espanha) e Milão (Itália). Professor de Direito Penal e Direito Processual Penal da EMERJ e da FEMPERJ. Advogado criminalista.
} 
possibilidades, que vem sendo amplamente explorado, e a sua influência sobre os diversos ramos do direito é notada, inclusive, no Direito Penal, como a moderna formulação do Direito Penal Internacional e do Direito Penal Econômico.

Paralelamente, no âmbito do direito interno, desenvolveu-se o constitucionalismo e, segundo a sua formulação contemporânea, a Constituição passa a funcionar como norma fundante e fundamental do Estado Democrático (Constitucional) de Direito. Ademais, também se presta como parâmetro de validade para as demais normas jurídicas, por força de sua supremacia e força normativa, exigindo uma interpretação da normatividade infraconstitucional em conformidade com a constitucional $^{2}$ (filtragem constitucional) $^{3}$ a partir do vetor da dignidade da pessoa humana, que é densificado pelos direitos fundamentais. Conseqüentemente, também há reflexos destas formulações contemporâneas da constitucionalização do direito nos seus diversos ramos, inclusive no Direito Penal.

Com efeito, surge a necessidade do estudo sobre a relação entre o direito internacional e o direito interno, em seu plano constitucional, para permitir o estudo das pena previstas no Estatuto de Roma (ER) a partir do filtro axiológico da Constituição da República Federativa do Brasil de 1988 (CRFB/88).

\section{O DIREITO PENAL INTERNACIONAL E O DIREITO CONSTITUCIONAL}

\subsection{Direito Penal Internacional}

Conforme observa Carlos Eduardo Adriano Japiassú, o Direito Penal Internacional é fruto da convergência entre a necessidade de aplicação internacional das regras penais internas e a existência de aspectos penais nas normas internacionais, o que levou à internacionalização da prevenção e repressão ao crime. ${ }^{4}$ Modernamente e a

\footnotetext{
${ }^{2}$ Conforme observa Lênio Streck, “a interpretação conforme a Constituição é mais do que princípio, é um princípio imanente da Constituição, até porque não há nada mais imanente a uma Constituição do que a obrigação de que todos os textos normativos do sistema sejam interpretados de acordo com ela". STRECK, Lênio. Hermenêutica jurídica em crise. Porto Alegre: Livraria do Advogado, 1999, p. 221.

${ }^{3}$ SCHIER, Paulo Ricardo. Filtragem constitucional: construindo uma nova dogmática jurídica. Porto Alegre: Sergio Antonio Fabris Editor, 1999, p. 61-84.

${ }^{4}$ JAPIASSÚ, Carlos Eduardo Adriano. Tribunal Penal Internacional: a internacionalização do direito penal. Rio de Janeiro: Lúmen Júris, 2004, p. 14-16.
} 
partir de uma visão monolítica ${ }^{5}$, o Direito Penal Internacional pode ser entendido como ramo do direito público que estabelece o conjunto de normas jurídicas (regras e princípios) de cunho material ou substancial (definição dos crimes internacionais, próprios e impróprios, por exemplo) e formal ou procedimental (tal como a disciplina dos tribunais penais internacionais ou regionais). Neste contexto, o ER instituiu o Tribunal Penal Internacional e, em seu o Capítulo VII, disciplinou as questões relacionadas às penas.

\subsection{Constitucionalismo}

São duas as fases do constitucionalismo: a fase pré-jurídica e a fase jurídica. A fase pré-jurídica se desenvolveu nas Idades Antiga (Antiguidade), Média e Moderna e compreendeu o período do legicentrismo (influência filosófica do jusnaturalismo), no qual a idéia de Constituição revelava apenas um conteúdo político e sem qualquer força normativa. As revoluções liberais (francesa e americana) marcam o início da Idade Contemporânea (Pós-modernidade), que guarda identidade com a fase jurídica do constitucionalismo, e se divide em dois períodos: o período do constitucionalismo clássico (influência filosófica do positivismo) e o período do constitucionalismo contemporâneo ou neoconstitucionalismo (influência filosófica do pós-positivismo). Modernamente, o constitucionalismo pode ser compreendido como o movimento histórico, filosófico e jurídico que desenvolveu a idéia de que todo Estado deveria possuir um documento fundamental (Constituição escrita), que contivesse a disciplina sobre a estrutura fundamental do Estado, consubstanciada na organização do Estado e na limitação do poder estatal pela tutela de direitos e garantias fundamentais (Constituição material); período este que, dada a sua densidade principiológica, revela algumas características que influenciarão decisivamente quando da proposição da solução ao conflito entre a projeção internacional e nacional, constitucional, da ordem jurídica: (i) a natureza jurídica da Constituição, que não representa um mero instrumento político (período do legicentrismo) ou um simples instrumento formalmente normativo (período do constitucionalismo clássico), mas um instrumento formal e materialmente normativo, o que lhe confere supremacia formal e material

\footnotetext{
${ }^{5}$ Ibid., p. 21.
} 
sobre as demais normas jurídicas, inclusive, de cunho internacional; (ii) o processo de descodificação e a criação de microssistemas normativos ("fattispecie", na Itália, ou "tatbestand", na Alemanha), que não apenas fortalece da idéia de força normativa da constituição, mas também como afirma a posição da constituição como a norma jurídica central; e (iii) o fortalecimento da interpretação constitucional, âmbito no qual é desenvolvida uma nova dogmática da interpretação constitucional.

\subsubsection{Direitos fundamentais}

A existência de uma teoria dos direitos fundamentais possui fundamento de três ordens: (i) filosófica, porque ligada tanto ao jusnaturalismo (são da natureza do ser humano; derivam de sua racionalização) como ao positivismo (estão previstos em constituições e tratados internacionais; derivam da sua positivação); (ii) sociológica (são decorrentes de fatos sociais; derivam da cultura do ser humano); e (iii) jurídica (derivam do diálogo, da argumentação e do discurso).

Nesta linha, os direitos fundamentais se revelam, para o Direito Penal, num conjunto institucionalizado de direitos subjetivos e garantias fundamentais do ser humano para a sua proteção contra o arbítrio do poder estatal (direito de defesa), de forma que a matriz constitucional penal deve ser lida a partir da atual compreensão sobre os direitos fundamentais, em especial a teoria dos quatro status (Jellinek), segundo a qual o indivíduo pode encontrar-se em face do Estado em algumas posições jurídicas: (i) status negativo, que guarda relação com os direitos de defesa ou de liberdade e exige uma atuação negativa (abstenção) por parte do Estado; ${ }^{6}$ (ii) status positivo ou civitatis, que guarda relação com os direitos prestacionais ou cívicos e que exige uma atuação positiva (prestação) por parte do Estado; (iii) status ativo, que guarda relação com o direito de participação na formação da vontade do Estado (direitos políticos); e (iv) status passivo ou subjectionis, que guarda relação com os deveres para com o Estado, veiculados através de mandamentos e proibições. ${ }^{7}$

\footnotetext{
${ }^{6}$ É nesta vertente que se encontra o espaço constitucional ocupado, por excelência, pela matriz constitucional penal porque impõe uma limitação ao poder do Estado na esfera de liberdade, e tem, como um de seus desdobramentos, a pretensão de que determinadas posições jurídicas não sejam eliminadas.

${ }^{7}$ COELHO, Inocêncio Martines; MENDES, Gilmar Ferreira; BRANCO, Paulo Gustavo Gonet. Curso de Direito Constitucional. São Paulo: Saraiva, 2007, p. 245.
} 
Os direitos fundamentais também revelam um núcleo essencial - âmbito ou núcleo de proteção (“schutzbereich”) -, que é revelado pelo princípio da dignidade da pessoa humana, e densificado pelos direitos fundamentais. Este núcleo exige uma vinculação constitucional ampla, inclusive, no campo da interpretação, impondo a adoção da técnica de interpretação restritiva a fim de preservar, ao máximo, a substância do direito fundamental.

\section{ORDEM JURÍDICA, DIREITO INTERNACIONAL E DIREITO INTERNO CONSTITUCIONAL}

Concebido um direito internacional distinto de um direito interno, surgiram duas concepções sobre a sua interação. A teoria dualista para a qual as ordens jurídicas interna e internacional compõem sistemas jurídicos distintos, independentes e sem qualquer interseção, de modo que não haveria conflito possível entre elas; e a teoria monista, para a qual a ordem jurídica é una, possuindo uma projeção interna normatividade interna - e outra internacional - normatividade internacional -, havendo a necessidade de compatibilizá-las e harmonizá-las.

Adotada a concepção monista e sedimentado o constitucionalismo, eventual colisão entre as projeções internacional e interna constitucional da ordem jurídica, prevalecerá sempre a normatividade interna constitucional sobre a normatividade internacional, com fundamento na supremacia e força normativa da constituição, de forma que não há espaço para a construção de outras soluções, sequer pela primazia da normatividade internacional mais benéfica ao ser humano. ${ }^{8}$

Com efeito, por razões históricas, filosóficas e jurídicas, as disposições da normatividade internacional devem estar em conformidade com a normatividade interna constitucional; caso contrário, mister promover a sua compatibilização e harmonização, sob pena de invalidação em seu grau máximo (inconstitucionalidade) da normatividade internacional e preservação da normatividade interna constitucional.

\footnotetext{
${ }^{8}$ CANÇADO TRINDADE, Antônio Augusto. Memorial em prol de uma nova mentalidade quanto à proteção dos direitos humanos no plano internacional e nacional. In BOUCAULT, Carlos Eduardo de Abreu; ARAÚJO, Nádia de (org.). Os direitos humanos e o direito internacional. Rio de Janeiro: Renovar, 1999, p. 42-49.
} 


\section{O SISTEMA DA PENA DO ESTATUTO DE ROMA E A CONSTITUIÇÃO DA REPÚBLICA FEDERATIVA DE 1988}

Partindo das premissas da afirmação histórica do Direito Penal Internacional e da consolidação do constitucionalismo, conclui-se pela necessidade do estudo do ER a partir da CRFB/88, que será limitado às disposições relativas à pena. Pela leitura deste capítulo em cotejo com as demais disposições do ER, sob o filtro da CRFB/88, quatro questões merecem atenção: (i) a disposição sobre a prisão perpétua (artigo $77, \S 1^{\text {o }}$, alínea "a", do ER); (ii) a disposição sobre a aplicação da pena (artigo 77, § 1º, do ER); (iii) a disposição sobre a determinação da pena (artigo 76 combinado com o artigo 78, todos do ER); e (iv) a disposição sobre a imprescritibilidade (art. 29, do ER).

\subsection{A prisão perpétua e o princípio da humanidade}

O ER estabeleceu, como uma de suas penas principais, a pena de prisão perpétua (artigo 77, § 1º, alínea “b”).

Ocorre que a CRFB/88, pela vontade do próprio Poder Constituinte Originário, afastou expressamente esta espécie de pena (artigo $5^{\circ}$, inciso XLVII) ${ }^{9}{ }^{10}$, lembrando que esta disposição se insere dentro das limitações materiais - cláusulas pétreas - (artigo 60, $\S 4^{\circ}$, inciso IV, da CRFB/88), razão pela qual sequer pode ser objeto de deliberação pelo Poder Constituinte Derivado. Outrossim, há previsão implícita na CRFB/88 quanto ao princípio da humanidade, segundo o qual há vedação de cominação, aplicação e

\footnotetext{
9 Vale destacar a evolução histórica da jurisprudência do Supremo Tribunal Federal (STF) sobre a aplicabilidade das normas de direito interno no âmbito internacional. Num primeiro momento, o STF concebia que a extensão da normatividade interna estaria limitada no âmbito interno, apenas, e inaplicável no âmbito internacional. Ocorre que esta interpretação evoluiu e, contemporaneamente, a jurisprudência do STF é no sentido de que a normatividade interna, precipuamente a constitucional, é aplicável tanto no âmbito interno como no âmbito internacional. Neste sentido também caminha a jurisprudência do Superior Tribunal de Justiça quando determina, por exemplo, a aplicação do Código de Proteção e Defesa do Consumidor aos contratos celebrados no exterior, tendo por fundamento se tratar de norma de ordem pública.

${ }^{10}$ No panorama do constitucionalismo brasileiro, observa-se que desde a Constituição de 1934, a ordem constitucional veda a pena de prisão perpétua: artigo 134, inciso 24, da Constituição de 1934; artigo 113, inciso XIII, da Constituição de 1937; artigo 141, § 31, da Constituição de 1946; artigo 150, § 11, da Constituição de 1967; artigo 153, § 11, da emenda constitucional de 1969; e, por fim, no artigo $5^{\circ}$, inciso XVLII, alínea "b", da Constituição da República Federativa do Brasil de 1988. No estudo do direito estrangeiro (países também signatários do ER), observa-se a adoção de idêntica disposição no artigo 17, da Constituição da Bolívia; o artigo 40, da Constituição da Costa Rica; o artigo XXX, da Constituição da Espanha; o artigo 30.1, da Constituição de Portugal; e o artigo 65, da Constituição da Venezuela.
} 
execução de pena degradante à moral e à integridade física do sujeito, e tem por fundamentos o princípio da dignidade da pessoa humana (artigo $1^{\circ}$, inciso III), o princípio da racionalidade (decorrente do próprio princípio da dignidade da pessoa humana), e o princípio da proporcionalidade (implícito na CRFB/88).

Com efeito, o artigo 77, § 1º, alínea “b”, do ER está em desconformidade com a CRFB/88. ${ }^{11}$ Ademais, não reside qualquer forma de compatibilização ou harmonização dos preceitos em comento, seja com os critérios tradicionais ou contemporâneos de interpretação constitucional, o que se concluir por sua invalidade.

\subsection{A aplicação da pena e o princípio da legalidade}

O ER não adotou a técnica legislativa comum nas ordens internas quando da elaboração dos tipos penais, mediante a separação do preceito primário (descrição do comportamento vedado) e preceito secundário (sansão correspondente) ${ }^{12}$ porque, para a identificação das penas possíveis, será necessária a combinação dos $\operatorname{artigos} 6^{\circ}$ a $8^{\circ}$ com o artigo 77 , todos do ER.

A Constituição, por sua vez, pelo princípio da legalidade (artigo $5^{\circ}$, II, da CRFB/88), determina que o Estado só pode interferir na esfera de liberdade do indivíduo quando este cometer um fato tido como crime. Tradicionalmente, interpretase esta disposição com base nos princípio da liberdade (autorização primária ao Estado para intervir em certas áreas), da segurança e estabilidade das relações jurídicas (prévio conhecimento do crime e da pena, bem como impede coerção penal diversa da lei) e da legitimidade democrática de intervenção na liberdade individual, por força do princípio da separação e harmonia entre os Poderes. A partir desta diretriz principiológica, o Poder Legislativo deveria indicar, num mesmo artigo, os preceitos primário e secundário, de forma a adotar um modelo que atenda um padrão de certeza e de restrições de pena exigidos por questões de segurança e estabilidade.

\footnotetext{
${ }^{11}$ Neste sentido: Luiz Vicente Cernicchiaro, Cezar Roberto Bitencourt, Luiz Luisi e Carlos Eduardo Adriano Japiassú (JAPIASSÚ. Op cit., p. 203). Contra: Flávia Piovesan e Antônio Augusto Cançado Trindade (PIOVESAN, Flávia. Direitos humanos e o Direito Constitucional Internacional. $7^{\mathrm{a}}$ ed. rev., ampl. e atual. São Paulo: Saraiva, 2006, p. 111 e JAPIASSÚ. Op. cit., p. 202) por entenderem que os documentos internacionais que versem sobre direitos humanos possuem hierarquia constitucional.

${ }^{12}$ Como, por exemplo, na Argentina, no Brasil, na Bolívia, no Chile, em Cuba, na Espanha, no Equador, na França, na Itália, no Japão, em Portugal, na Rússia e na Venezuela.
} 
Entretanto, por se tratar de um documento internacional, há uma dificuldade prática de harmonização de tensões dogmáticas, o que impõe não apenas a sua flexibilização, mas também a sua interpretação a partir das diretrizes do próprio póspositivismo. Da compreensão e da distinção entre regras e princípios, a lei seria o mero veículo formal da norma; desta forma, caberia ao órgão julgador perquirir, dentro do ordenamento jurídico, a norma aplicável ao caso concreto. Não foi por outra razão que Paulo Ricardo Schier observou que a abertura do sistema jurídico-constitucional possibilita a evolução e substituição dos valores, pois “... o Direito, como um sistema dinâmico, em constante evolução e construção, em constante diálogo com as realidades sociais, econômicas e jurídicas,...". ${ }^{13}$ Com efeito, esta posição do órgão julgador estaria em perfeita adequação ao seu papel constitucional, uma vez que estaria apenas revelando o conteúdo e alcance das normas. Por esta razão, Winfried Hassemer afirma que "a norma não pode ser compreendida sem uma concepção das circunstâncias nas quais ela deve ser 'encaixada", 14

Portanto, o artigo $77, \S 1^{\circ}$, do ER guarda compatibilidade com a CRFB/88 porque acompanha a construção jurídica atual sobre as técnicas legislativas, não sendo necessária qualquer compatibilização ou harmonização, muita menos a sua invalidação.

\subsection{A determinação da pena e o princípio da individualização da pena}

O ER, em seu artigo $77, \S \S 1^{\circ}$ e $2^{\circ}$, optou por técnica legislativa de fixação somente da pena máxima e sem estabelecimento de um mínimo, o que, a partir de uma análise de direito comparado, pode parecer um equívoco por não haver a indicação da escala penal, tal conforme há no Brasil.

Pelo princípio da individualização da pena (artigo $5^{\circ}$, inciso XLVII, da CRFB/88), impõe-se a eleição da justa e da adequada sanção penal, quanto ao montante, ao perfil e aos efeitos pendentes sobre o sentenciado, tornando-o único e distinto dos demais infratores. Pode-se identificar, na história do direito e no direito comparado, diversos modos ou formas de individualização da pena. A doutrina aponta quatro: (i) sistema da pena fixa ou determinada pela lei (pena absolutamente determinada), que não

\footnotetext{
${ }^{13}$ SCHIER. Op cit., p. 90.

${ }^{14}$ HASSEMER, Winfried. Direito penal: fundamentos, estrutura, política. Carlos Eduardo de Oliveira Vasconcelos (org.). Porto Alegre. Sergio Antonio Fabris Editor, 2008, p. 93.
} 
dá margem de escolha ao órgão julgador; (ii) sistema da pena totalmente indeterminada (pena absolutamente indeterminada), permitindo ao órgão julgador fixar a quantidade de pena; (iii) sistema da pena relativamente indeterminada (pena relativamente indeterminada), por vezes fixando somente o máximo e sem estabelecer um mínimo; e (iv) sistema da pena estabelecida em lei dentro de margens mínima e máxima (penas relativamente determinadas), cabendo ao órgão julgador a sua definição.

Neste contexto, percebe-se o artigo $77, \S \S 1^{\circ}$ e $2^{\circ}$, do ER, adotou o sistema da pena relativamente indeterminada, optando pela técnica legislativa de fixação somente da pena máxima. Por outro lado, como se trata de relação de direito internacional, devese levar em consideração as diversidades culturais, sociais etc. dos países signatários, razão pela qual a opção por um sistema penal que confira uma discricionariedade mais alargada ao órgão julgador poderá, no caso concreto, aproximar a solução proposta da idéia de justiça ${ }^{15}$, sendo esta a tendência do atual cenário político criminal. ${ }^{16}$

\subsection{A imprescritibilidade e os princípios do Estado democrático de direito e da segurança e estabilidade das relações jurídicas}

O artigo 29, do ER dispõe que todos os crimes internacionais contemplados em suas disposições são imprescritíveis.

Para a exata compreensão de sua conformidade ou não com a CRFB/88, devese, inicialmente, compreender a idéia de prescrição e de imprescritibilidade. A prescrição penal é a perda da pretensão punitiva ou executória do Estado em razão de sua inércia e pelo decurso do tempo, funcionando como uma causa de extinção da punibilidade de um crime ou contravenção (artigo 107, IV, do CP); portanto, instituto de ordem pública e de natureza substancial ou material, uma vez que afeta o direito de liberdade. Revela, portanto, um duplo aspecto: ao passo que a incidência da prescrição prejudica o Estado no exercício do seu direito de ação penal, também beneficia o indivíduo, uma vez que lhe preserva e consolida o exercício pleno do seu direito de liberdade. A imprescritibilidade, por outro lado, é a situação diametralmente oposta porque ao permitir que o Estado, a qualquer tempo, promova a ação penal, impede o exercício do direito de liberdade pela promoção de acentuado grau da sensação de

\footnotetext{
${ }^{15}$ Presente, também, em diversas ordens internas, tal como na Itália.

${ }^{16}$ HASSEMER. Op. cit., p. 143.
} 
insegurança pública e desestabilização social; num ambiente de pós-modernidade, marcada pela juridicidade e pela ampla liberdade pública, é completamente ilegítimo que a própria ordem jurídica, constitucional e legal, fomente a incompetência do Governo e a ineficiência do Estado em detrimento dos direitos e das garantias fundamentais dos indivíduos, especialmente quando há referência aos direitos substancialmente mais caros, como é o direito de liberdade.

Ao lado destas considerações, o Poder Constituinte Originário estabeleceu apenas duas hipóteses de imprescritibilidade: o crime de racismo (artigo $5^{\circ}$, XLII) e o crime contra a ordem constitucional e o Estado Democrático (artigo 5, XLIV). Desta forma, a regra constitucional é a da prescritibilidade, salvo em duas situações excepcionais, como forma de densificar o princípio da segurança e estabilidade das relações sociais e, conseqüentemente, promover o direito de liberdade.

Neste ponto, duas questões relacionadas com os direitos fundamentais revelam a sua importância. No que se refere à técnica interpretativa, conforme já registrado, qualquer interpretação que imponha restrição aos direitos fundamentais, deve ser restritiva para que se preserve, ao máximo, o seu conteúdo. Uma segunda consideração, mais importante, sobre a projeção do status negativo dos direitos fundamentais porque, a partir do momento em que o instituto da prescrição penal guarda natureza substancial ou material, atingindo o direito de liberdade, revela o seu assento constitucional; ou seja, a prescrição penal, por encontrar fundamento não apenas no princípio do Estado Democrático de Direito (artigo $1^{\circ}$, caput, da CRFB/88, revelador da paz pública e da segurança e estabilidade das relações jurídicas), também encontra fundamento constitucional no direito da liberdade, expresso no caput, do artigo $5^{\circ}$, da CRFB/88, que foi erigido a direito fundamental. Nesta ordem de idéias, pode-se afirmar que a prescritibilidade, por ser expressão do direito fundamental de liberdade (artigo $5^{\circ}$, caput, da $\mathrm{CRFB} / 88$ ), é cláusula pétrea (artigo 60, $\S 4^{\circ}, \mathrm{IV}$, da $\mathrm{CRFB} / 88$ ), sendo vedada a sua remoção ou modificação. ${ }^{17}$

\footnotetext{
${ }^{17}$ Conforme observa Oscar Vilhena Vieira, neste ponto há divergência na doutrina. A profundidade da cláusula pétrea revelada pela expressão "tendente a abolir" constante do artigo 60, da CRFB/88 recebe três interpretações. A primeira interpretação é no sentido de que não é possível qualquer acréscimo ou redução, pois a identidade da Constituição já estaria formada; uma segunda interpretação realizada por parte da doutrina é no sentido de se admitir, porém, apenas acréscimo quando se trate de explicitação de limite material implícito; e, por fim, uma terceira e última interpretação possível no sentido de se admitir até a redução, desde que seja de pequena monta, respeitado o princípio da razoabilidade; o núcleo básico e fundamental não pode ser alterado ("limites dos limites"), os institutos e valores podem ser atingidos.
} 
Portanto, o artigo 29, do ER não está em conformidade com a normatividade interna constitucional porque prevê hipóteses de imprescritibilidade não contempladas pela CRFB/88, além de não possuir o condão de remover ou modificar o conteúdo das disposições constitucionais confrontantes. Com efeito, a preservação deste dispositivo estatutário com a normatividade interna constitucional exige a sua interpretação conforme a CRFB/88, extraindo-se, por conseguinte, que a única interpretação compatível e harmônica com a CRFB/88 é admitir a imprescritibilidade dos crimes previstos no ER apenas quando guardarem relação com racismo ou com a ofensa a normatividade constitucional e o Estado Democrático, tal como ocorre, por exemplo, no crime de genocídio praticado com a intenção de destruir um grupo racial, em todo ou em parte (artigo $6^{\circ}$, do ER).

\section{CONCLUSÕES}

1. Durante a pós-modernidade, dois grandes movimentos marcaram o direito: a afirmação histórica do direito internacional e a sedimentação do constitucionalismo.

2. Da relação entre a projeção internacional e interna da ordem jurídica, em razão da supremacia e força normativa da constituição, eventual conflito entre as disposições deverá ser solucionado a partir do filtro axiológico constitucional. Por conseguinte, as normas do ER devem guardar conformidade com a CRFB/88, sob pena de invalidação.

3. Da análise do ER conforme a CRFB/88, percebe-se que (i) embora o sistema de penas adotado pelo ER não guarde correspondência com a maior parte da disciplina interna dos Estados signatários, revela desconformidade apenas no tocante a pena de prisão perpétua, razão pela qual é inválida (inconstitucional); (ii) exige interpretação conforme em relação a disciplina da imprescritibilidade a fim promover a sua conformação e harmonização; e, por fim, (iii) suas disposições referentes a determinação e aplicação da pena estão em conformidade com a normatividade interna constitucional brasileira.

Ocorre que, para a parte doutrinária que admite modificações, se exige que a alteração seja realizada por meio de emenda constitucional, jamais atos infraconstitucionais como os provenientes da normatividade internacional com o Estatuto de Roma. VIEIRA, Oscar Vilhena. A Constituição e sua reserva de justiça: um ensaio sobre os limites materiais do poder de reforma. São Paulo: Malheiros, 1999, p. 134-140. 
4. A globalização econômica e a integração regional vêm promovendo um incrível incremento dos meios de transporte e de comunicação, bem como o acentuado o desenvolvimento e acúmulo dos recursos econômicos e financeiros. Com efeito, esta mobilidade das pessoas tem resultado a progressiva internacionalização do crime, o que refletirá na consolidação de uma jurisdição penal internacional permanente direcionado à promoção dos direitos humanos e respeito à dignidade da pessoa humana -, porém, será necessário um esforço contínuo e progressivo por parte dos intérpretes na tentativa de conferir a máxima efetividade possível aos diplomas internacionais, e dos Estados para que se evite a elaboração de normatividade internacional em desconformidade com a normatividade interna constitucional, sob pena de incremento da insegurança característica da sociedade de risco, transmutando o Estado de direito no Estado de risco.

\section{REFERÊNCIAS}

ALEXY, Robert. Teoria de los derechos fundamentales. Madrid: Centro de Estúdios Políticos y Constitucionales, 2002.

AMBOS, Kai; CARVAlHO, Salo de (org.) O Direito Penal no Estatuto de Roma Leituras Sobre os Fundamentos e a Aplicabilidade do Tribunal Penal Internacional. Rio de Janeiro: Lúmen Juris, 2005.

; JAPIASSÚ, Carlos Eduardo Adriano (org.). Tribunal Penal Internacional Possibilidades e Desafios. Rio de Janeiro: Lúmen Juris, 2005.

BARROSO, Luís Roberto. Neoconstitucionalismo e constitucionalização do direito (o triunfo tardio do direito constitucional no Brasil). Revista de Direito Constitucional e Internacional nº 58/129. São Paulo: Revista dos Tribunais, 2007.

BOUCAULT, Carlos Eduardo de Abreu; ARAÚJO, Nádia de (org.). Os direitos humanos e o direito internacional. Rio de Janeiro: Renovar, 1999. 
CHOUKR, Fauzi Hassan, AMBOS, Kai (org.). Tribunal Penal Internacional. São Paulo: Revista dos Tribunais, 2000.

COELHO, Inocêncio Martines; MENDES, Gilmar Ferreira; BRANCO, Paulo Gustavo Gonet. Curso de Direito Constitucional. São Paulo: Saraiva, 2007.

HASSEMER, Winfried. Direito penal: fundamentos, estrutura, política. Carlos Eduardo de Oliveira Vasconcelos (org.). Porto Alegre. Sergio Antonio Fabris Editor, 2008.

JAPIASSÚ, Carlos Eduardo Adriano. Tribunal Penal Internacional: a internacionalização do direito penal. Rio de Janeiro: Lúmen Júris, 2004.

PIOVESAN, Flávia. Direitos humanos e o Direito Constitucional Internacional. $7^{\mathrm{a}}$ ed. rev., ampl. e atual. São Paulo: Saraiva, 2006.

Direitos humanos, globalização econômica e integração regional: desafios do Direito Constitucional Internacional. São Paulo: Max Limonand, 2002.

SCHIER, Paulo Ricardo. Filtragem constitucional: construindo uma nova dogmática jurídica. Porto Alegre: Sergio Antonio Fabris Editor, 1999.

SOUZA, Artur de Brito Gueiros. Presos estrangeiros no Brasil- aspectos jurídicos e criminológicos. Rio de Janeiro: Lumen Juris, 2007.

STRECK, Lênio. Hermenêutica jurídica em Crise. Porto Alegre: Livraria do Advogado, 1999.

VIEIRA, Oscar Vilhena. A Constituição e sua reserva de justiça: um ensaio sobre os limites materiais do poder de reforma. São Paulo: Malheiros, 1999. 